\title{
THE RELATIONSHIP BETWEEN PROCRASTINATION AND CREATIVE THINKING
}

\author{
Katerina Rumyantseva \\ Ph.D., Assistant Professor, West Ukrainian National University, Ukraine \\ e-mail: rumyanceva@ukr.net, orcid.org/0000-0003-2423-5608
}

\section{Larysa Movchan}

Ph.D., Assistant Professor, Vinnytsia Humanities Pedagogical College, Ukraine e-mail: larisa.movchan.ua@gmail.com, orcid.org/0000-0003-0913-3240

\section{Summary}

The article considers the issue of the relationship between the phenomenon of procrastination and creative thinking. One of the most common factors that hinder personal and professional effectiveness is procrastination. There is a hypothesis that people with high levels of procrastination have correspondingly well-developed creative thinking, which endows them with the ability to solve problems outside the box and quickly adapt to situations. 1 We consider procrastination as a psychological pattern of behavior characterized by person's delaying planned actions or decision-making followed by negative emotional experiences. Literature analysis has shown that procrastination influences creative activity, which leads to the assumption that people with higher levels of procrastination have a higher level of creativity.

Upon conducting our research, we uncovered the following pattern: students with a high level of procrastination are more inclined to such factors as risk-taking and fantasy; students with a low level are more likely to present curiosity and task complexity; and students with an average level of procrastination are equally likely to present both factors.

Keywords: procrastination, creative thinking, creative activity, creativity.

\section{DOI: https://doi.org/10.23856/4809}

For a modern person living in a rapidly changing world, issues of personal effectiveness, success and well-being are of particular importance. But often, despite an increasingly wide range of opportunities and individual freedom, a person faces barriers to his success. One of the most common factors that hinder personal and professional effectiveness is procrastination. The relevance of this problem and the tendency to spread it have attracted the attention of modern scientists in the field of psychology, however, many issues related to the phenomenon of procrastination are now debatable and require in-depth study and detailed analysis of this phenomenon. In life, there emerge circumstances and changes that need to be overcome, and a person with creative, unconventional thinking is ready for this. This person does not only adapt to something new, but also takes part in planning and changing the surrounding reality. There is a hypothesis that people with high levels of procrastination have correspondingly well-developed creative thinking, which endows them with the ability to solve problems outside the box and quickly adapt to situations.

Now the number of procrastinating young people is growing. According to the data, between 80 and $95 \%$ students of higher educational establishments procrastinate from time to time, and approximately $75 \%$ of them consider themselves "chronic procrastinators" and almost $50 \%$ of students postpone important things systematically. There is a stereotypical view 
of procrastination as a negative phenomenon, which is reflected in the study of the relationship between creative thinking and procrastination. The connection of these manifestations is a poorly studied area and is regarded mainly by foreign authors as the influence of procrastination on creativity. The available theoretical data reflect the ambiguous attitude of scientists to the problem of the influence of procrastination on creative thinking.

The aim of our research is to analyze and empirically study the psychological features of the influence of procrastination levels on students' creative thinking. The hypothesis is based on the assumption that a person's level of procrastination affects the level of creative thinking.

Theoretical and methodological basis of research is made up bythe works of such researchers as V. Barabanshchikova, Ya. Varvarycheva, N. Vishnyakova, E. Ilyin, K. Lay, N. Milham, M. Spada, P. Steel, K. Taylor, E. Tunik, E. Thorens, B. Fernie, M. Kholodna and others.

The relationship between creative thinking and procrastination has been studied by different researchers using different approaches.

Some of them believe that procrastination can negatively affect creativity for two reasons. First, research consistently shows that procrastination has a negative impact on academic performance. At the same time, academic performance is positively associated with creativity, it is believed that procrastination harms creative activity. Secondly, the anxiety caused by procrastination impairs creativity. In particular, studies have shown that procrastination is positively correlated with anxiety, anxious people tend to have low scores in divergent thinking, the index of which is widely used in creative research. So, let's assume that procrastination is indirectly harmful to creativity due to anxiety (Motruk, 2014).

Other researchers have found that procrastination is positively associated with creativity, as it helps people have more time to brood ideas. Postponing tasks for some time contributes to the remote unification of ideas, therefore, people are more likely to generate new answers (Varvaricheva, 2008).

In addition, Diaz-Morales and colleagues have shown that the beneficial effects of procrastination on creativity may be associated with a preference for visual thinking. They examined the effects of a person's motivational, cognitive, and behavioral styles on task postponement. People feel that they do not have enough competence to complete a task, so they postpone it "for later". An analysis of 1,027 adult self-reports showed that procrastinators with high procrastination rates had higher grades.

British psychologists B. Fernie and M. Spada concluded that procrastination stimulates the creativity of the individual, that is, a person is able to create a more original idea, postponing sorting out a problem situation for later.

B. Fernie and M. Spada conducted a study and found that procrastinators often resort to using positive and negative attitudes to overcome stress. Creative procrastinators resort to positive attitudes. Fernie and Spada believe that difficult decisions should be made slowly (Motruk, 2014). This increases not only the quality of solving a problem situation, but also the speed of making the right decision. If all the possible aspects of the situations are considered, a person does not need to return to the process of decision making. A procrastinator, like any other person, postpones only those activities that can be postponed. In an extreme situation, even chronic procrastinators will be very agile and show fairly high speed in the decision-making process (Varvaricheva, 2010).

There are many examples in history when famous creative people were distinguished by pronounced procrastination. Contemporaries noted their tendency to laziness and relaxation, but their highly productive creative activity can hardly be combined with a lack of strong-willed efforts. They probably reacted with procrastination to situations that little depended on the speed 
of solving in their creative life. Those aspects of life that seemed unimportant and optional did not motivate them to create. Therefore, they postponed solving problems. Another reason for the connection between procrastination and creativity is the desire to bring the creative product to the standard. The standard is most often a variable internal standard, and therefore a person is forced to postpone the final completion of a creative product, because the idea of an ideal result in the course of creative work is constantly changing. Therefore, many famous works of art were created longer than it had been intended. Many of them remained unfinished. A creative and a non-creative persons procrastinate for different purposes, thus using their procrastination in a different way. The creative person sees procrastination as a potential for development, and a non-creative person as an obstacle to self-improvement. Procrastination can interfere with a creative personality if a creative identity is not developed yet, which enables to integrate all personal resources for creative activity. It is creative identity that forms a positive attitude to procrastination as a strategy for creative solution of a problem situation (Motruk, 2014).

For creative people, in our opinion, procrastination is not just a delay in completing a task. We believe that during the procrastination period, the creative person has already started performing a task that is latent, although in behavioral terms, the person can be busy with things that are only indirectly related to the task while the work is already being done. This is a kind of creative procrastination - hidden performance of work with external abstraction from the task and pronounced procrastination behavior. Creativity in this case is a way of procrastinating without negative experiences and feelings of anxiety. For example, a student was given a task to prepare a report with a presentation on a given topic, but he began to devote time to templates, presentation design, font selection, etc., thus, creating a feeling of activity, but without moving on to the final result for a long time. Perhaps we should highlight a new type of procrastination - "creative procrastination" - a situation in which creative procrastination can be traced, under the guise of creative activity.

Given all mentioned above, we think it is important to emphasize that there is a link between procrastination and creative thinking. Various authors consider this connection as the influence of procrastination on creativity. It should also be noted that authors' opinions on the effect of procrastination on creativity split between positive and negative.

Negative factors include: 1) academic performance, while academic performance is positively associated with creativity; 2) procrastination harms creative activity; 3) anxiety as a result of procrastination worsens creative potential.

In a positive impact, the following aspects can be considered: 1) procrastination enables to have more time for contemplation, therefore, people are more likely to generate new ideas; 2) positive connection is reflected in the preference for imaginative thinking style; 3) preference in choosing positive attitudes to deal with stress.

We consider procrastination as a psychological pattern of behavior characterized by person's delaying planned actions or decision-making followed by negative emotional experiences.

Procrastination, like creativity, does not have a clear definition, so it was considered from the point of view of various concepts that come down to the following: firstly, procrastination is associated with unresolved internal conflicts, traumas; secondly, with emotional states, irrational approach and infantilism. These factors correlate well with the concept of creativity, because all creative people are full of contradictions.

Literature analysis has shown that procrastination influences creative activity, which leads to the assumption that people with higher levels of procrastination have a higher level of creativity. 
After studying the theoretical data of procrastination, creative thinking and their connection, we formed a sample of 68 people, conducted an empirical study, selected diagnostic material in order to define the level of procrastination and creative thinking in students, as well as to find out what influence is exerted on the level of creative thinking depending on the level of procrastination of the individual. We used the following methods: the scale of total procrastination by K. Lay, Tuckman procrastination scale, self-assessment questionnaire for creative personality characteristics by E. Tunik, the test of creative (divergent) thinking by F. Williams.

We also used descriptive statistics of results using the methods " scale of total procrastination by K. Lay "and" Tuckman's procrastination scale", the results are presented in Table 1.

Table 1

Descriptive statistics of results according to the methods

"Scale of total procrastination by K. Lay" and "Tuckman's procrastination scale"

\begin{tabular}{|l|c|c|}
\hline \multirow{2}{*}{\multicolumn{1}{|c|}{ Parameter }} & \multicolumn{2}{c|}{ Value } \\
\cline { 2 - 3 } & Scale by K. Lay & Tuckman Scale \\
\hline Minimum & 30 & 29 \\
\hline Maximum & 73 & 60 \\
\hline Arithmetic mean & 49 & 43 \\
\hline Median & 46.5 & 43 \\
\hline Statistic mode & 44 & 44 \\
\hline Standard deviation & 10.8 & 8.38 \\
\hline Variance & 120.27 & 71.41 \\
\hline Asymmetry & -0.25 & -0.25 \\
\hline Excess & 0.76 & 0.36 \\
\hline
\end{tabular}

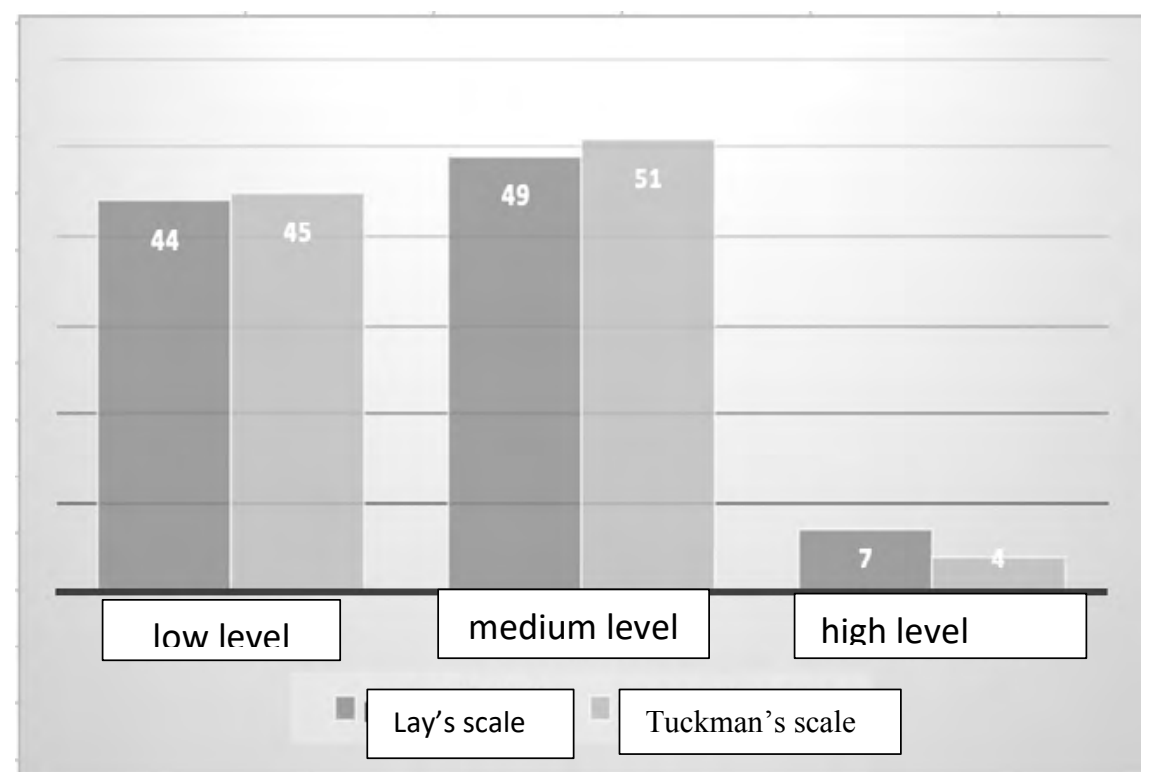

Fig. 1. Distribution of students by procrastination rate (as a percentage) 
Based on this, the minimum value of procrastination according to the method "Scale of total procrastination by K. Lay " was 30, the maximum - 73. The average indicator is 49 with a deviation of 10.8. By Tuckman procrastination scale, the minimum is 29 , the maximum is 60 , the arithmetic mean is 43 , and the standard deviation is 8.38 . The most common value is by the K scale. Lay (mode) 44; median - 46.5, on the Tuckman scale 44 and 43, respectively. Indicators of asymmetry and excess were below the significance level, which indicates the normality of the distribution and the possibility of using parametric criteria in data analysis.

Next, we set procrastination levels according to K. Lay total procrastination scale and "Tuckman procrastination scale" The study of the overall level of procrastination showed a prevailing average level of total procrastination in students. The analysis of the results is shown in Figure 1.

According to the interpretation of the results on the K. Lay's scale, the group with a low level of procrastination can include 30 persons - the results are less than 45 points. The average level includes 33 persons - the results of which are within the range from 46 to 65 points, and the high level includes 5 persons. The results in the figure are presented as a percentage. On the Tuckman scale, low levels of procrastination were found in 31 people, medium levels in 35 people, and high levels in 2 people.

Using the analysis of variance data and the linear correlation coefficient of the obtained data according to the methods " K. Lays' total procrastination scale" and "The test of creative (divergent) thinking by F. Williams", we defined how the level of procrastination affects the level of creative thinking.

Namely, based on the data obtained by the least squares method, we will determine the parameters $\mathrm{a}_{1}$ and $\mathrm{a}_{0}$ :

$a_{1}=0,14$

$a_{0}=60,8$

$$
\begin{gathered}
a_{1}=\frac{\sum\left(Y_{i}-\bar{Y}\right)\left(X_{i}-\bar{X}\right)}{\sum\left(X_{i}-\bar{X}\right)^{2}} \\
a_{0}=\bar{Y}-a_{1} \bar{X}
\end{gathered}
$$

Thus, the model of the relationship between the level of procrastination and creative thinking will be like that:

$$
y=0.14 x+60.8
$$

Let's calculate the tightness of the relationship between the level of procrastination and creative thinking. For this we will use the correlation coefficient:

$$
r=\frac{\frac{1}{n} \sum\left(Y_{i}-\bar{Y}\right)\left(X_{i}-\bar{X}\right)}{\sqrt{\frac{1}{n} \sum\left(X_{i}-\bar{X}\right)^{2} \frac{1}{n} \sum\left(Y_{i}-\bar{Y}\right)^{2}}}=\frac{\frac{1}{68} 1173.764}{\sqrt{\frac{1}{68} 8058.2353 \frac{1}{68} 11481.659}}=0.122
$$

The correlation coefficient shows that there is a direct $(r>0)$ weak relationship between the level of procrastination and creative thinking.

Let's check the model for adequacy to real reality using the coefficient of determination:

$$
R^{2}=r^{2}=0,14
$$

So, the model of relation of the level of procrastination to creative thinking is adequate.

Using the Fisher linear correlation criterion with reliability $p=0.95$, we evaluate the adequacy of the accepted model to experimental data with freedom degrees 1 and 11 and a 
significance level of 0.05 critical value $\mathrm{F}_{\mathrm{kr}}=4,84$. Since $\mathrm{F}_{(1.11)}>\mathrm{F}_{\mathrm{kr}}$ then the model is adequate to the experimental data. So, the level of personality procrastination affects the level of creative thinking, which confirms our hypothesis.

The analysis of the results of the study suggests that the level of creative thinking is directly influenced by the phenomenon of procrastination, so accordingly, people with a higher level of procrastination are more likely to be creative and having a creative approach to solving questions or completing tasks.

After identifying the dependence of the influence of the level of procrastination on the level of creative thinking, we compared the data of the "self-assessment questionnaire of creative characteristics of the individual by E. Tunik " and the level of students' general procrastination. The questionnaire contains 4 factors: curiosity, imagination, complexity, and risk-taking. So, for example, a subject with pronounced curiosity is constantly looking for new ways (ways) of thinking, looking for various ways to solve problems, pays attention to search and research activities in order to learn as much information as possible. A person with a developed imagination devotes a lot of time to fantasies about the ways of problem solving, wasting time on direct solutions. The person is focused on the knowledge of complex phenomena, shows interest in complex problems and ideas, and offers too complex ways to solve the problem than it seems necessary. Risk-taking is manifested in the fact that the person's performance will be better with the presence of a direct threat, which is the point of activated potential for action. The results of the study of factors are presented in Table 2.

Table 2

Results of the "Questionnaire of self-assessment of creative characteristics of the individual by E. Tunik" and the level of students' general procrastination

\begin{tabular}{|l|c|c|c|}
\hline \multicolumn{1}{|c|}{ Factor } & $\begin{array}{c}\text { Low procrastination } \\
\text { rate }\end{array}$ & $\begin{array}{c}\text { Average } \\
\text { procrastination rate }\end{array}$ & $\begin{array}{c}\text { High level } \\
\text { of procrastination }\end{array}$ \\
\hline Curiosity & $81 \%$ & $53 \%$ & $40 \%$ \\
\hline Imagination & $15 \%$ & $59 \%$ & $80 \%$ \\
\hline Complexity & $76 \%$ & $39 \%$ & $20 \%$ \\
\hline Inclination to risk-taking & $10 \%$ & $69 \%$ & $100 \%$ \\
\hline \multicolumn{3}{|r|}{ Frequency of factor occurrence } \\
\hline
\end{tabular}

As a result of analyzing the data obtained, it can be noted that students with a low level of procrastination are characterized by curiosity and ability to solve complex tasks. In other words, such individuals usually choose tasks of increased complexity, study the issue in detail from all sides, and try to complete the task on time and with the highest productivity coefficient. So, at the same time, they are not subject to risk and fantasy, they perform tasks clearly according to the rules and plan.

Students who are part of a group with an average level of procrastination are almost equally likely to possess these characteristics. The table shows that risk-taking and fantasy have a greater advantage than curiosity and task complexity, which may indicate that the first two characteristics play a distracting and time-wasting role. Students in this group are more likely to avoid difficult tasks and tend to fall behind with tasks completion.

The data obtained from groups with a high level of procrastination indicate that students spend a significant part of their time on such a factor as imagination or fantasy, respectively, they are prone to risk-taking because of lack of time. Usually, such individuals specifically 
provoke a situation of lack of time to complete a task, because only with a sense of tension do they mobilize the ability and desire to perform the postponed work. Also, such a factor as fantasizing is often used for figurative modeling of problem solving, that is, planning without practical actions. A characteristic of students with a high level of procrastination is that they do not choose very difficult tasks.

Upon conducting our research, we found the following pattern: students with a high level of procrastination are more inclined to such factors as risk-taking and fantasy; students with a low level are more likely to present curiosity and task complexity; and students with an average level of procrastination are equally likely to present both factors.

Naturally, the research carried out does not fully highlight all the aspects of this problem. Its results enable us to determine some areas of further research:

- to study and classify specific operational criteria for procrastination and their empirical substantiation;

- to develop algorithms for preventing the phenomenon of procrastination.

\section{References}

Motruk T. O., Stetsenko D. V. (2014). Prokrastynatsiya yak inhibitor rozvytku uspishnoyi osobystosti [Procrastination as an inhibitor of successful personality development]. Aktual'ni pytannya suchasnoyi psykholohiyi: materialy I Vseukrayins'koyi naukovo-praktychnoyi konferentsiyi studentiv, aspirantiv I molodykh vchenykh. Sumy: Vyd-vo SumDPU imeni A. S. Makarenka. Pp. 292-297. [in Ukrainian]

Varvaricheva Ya. I. (2010). Fenomen prokrastinatsii: problemy i perspektivy issledovaniya [The phenomenon of procrastination: problems and prospects of research]. Issues of psychology]. № 3. Pp. 121-131. [in Russian]

Varvaricheva Ya. I. (2008). Issledovaniye svyazi prokrastinatsii, trevozhnosti i IQ u shkol'nikov [Research on the connection of procrastination, anxiety and IQ in schoolchildren]. Materialy dokladov XV Mezhdunar. konf. studentov, aspirantov i molodykh uchenykh "Lomonosov». URL: http://psy.msu.ru/science/conference/ lomonosov/2008/theses/18_2.pdf. [in Russian] 